\title{
PERUBAHAN SUDUT POLARISASI ALAMI DAN ELEKTROOPTIS MINYAK SAWIT YANG DICAMPUR BERBAGAI MINYAK HEWANI
}

\author{
Hadiyati Idrus $^{1}$, Ummi Kaltsum ${ }^{2}$, K. Sofjan Firdausi ${ }^{3}$ \\ ${ }^{1)}$ Jurusan Tadris Fisika Fakultas Tarbiyah dan Ilmu Keguruan IAIN Batusangkar \\ ${ }^{2)}$ Jurusan Fisika FPMIPATI Universitas PGRI Semarang \\ ${ }^{3)}$ Jurusan Fisika, FMIPA Universitas Diponegoro Semarang \\ Email: hadiyatii@yahoo.com
}

\begin{abstract}
Palm oil-based cooking oil is the most widely used cooking oil. Palm oil circulating in the market is often mixed with animal oil by culinary entrepreneurs with a view to produce a more tasty taste so it needs to be examined purity. Research on the content of saturated fatty acids using gas chromatography mass spectrophotometer (GCMS) requires quite expensive cost so that an alternative method is needed to determine the quality of cooking oil; especially its purity is by using polarization both naturally and by electrooptic method. This research uses incandescent lamp as light source. Samples flanked by parallel metal plates are placed between polarizers and analyzers. Samples of a mixture of palm oil with each animal oil (chicken oil, pork oil, cow oil). The samples of each oil are tested byu using natural polarization (active polarization) and electropolarization polarization (impact polarization). The results showed that the polarization angle change in the oil of the mixture was greater than that of pure palm oil with the greatest angular change produced by a mixture of palm oil and cow oil (1.5 for natural polarization and 3 for electro-polarization). This result was in accordance with the result of the titration test shows that mixed oils have free fatty acids and PV peroxide numbers higher than pure palm oil. The cow's oil mix is the greatest change compared to pigs and chickens. This result shows that cow's oil has the highest saturated fatty acid content. Electrooptical polarization angle larger than natural polarization. This is due to the interaction of the electric field of the light source with the electric field of the molecule induced by the electric field of the power supply. The polarization method successfully distinguishes the type of pure and mixed cooking oil.
\end{abstract}

Key words: polarization, electrooptical, palm oil, animal oil

\section{PENDAHULUAN}

Minyak goreng yang sesuai Standar Nasional Indonesia (SNI) didefinisikan sebagai bahan pangan dengan komposisi utama trigliserida berasal dari bahan nabati kecuali kelapa sawit, dengan atau tanpa perubahan kimiawi, termasuk hidrogenasi, pendinginan dan telah melalui proses rafinasi/pemurnian yang digunakan untuk menggoreng (SNI, 2013). Asam lemak jenuh dan asam lemak tak jenuh merupakan bagian dari molekul trigliserida. Kenyataan di pasaran kebanyakan minyak goreng terbuat dari kelapa sawit dan sebagian kecil dari bahan hewani. Berdasarkan referensi lain, minyak goreng adalah minyak yang berasal dari lemak tumbuhan atau hewan yang dimurnikan dan berbentuk cair dalam suhu kamar dan biasanya digunakan untuk menggoreng makanan (Sitepoe, 2008). Definisi ini diperluas lagi sebagai sumber bahan 
pembuat minyak goreng bukan hanya berasal dari bahan nabati saja tetapi juga bahan hewani.

Ada beragam metode yang dilakukan untuk menguji mutu minyak goreng, diantaranya metode kromatografi kolom dengan sensor dielektrik, differential scanning calorimetric (DSC), NIR spectroscopy, refractometer fiber optic, FTIR, NMR, dan lain-lain (Firdausi, 2012). Firdausi (2012) juga menyebutkan bahwa metode-metode tersebut memerlukan peralatan yang mahal dan waktu yang cukup lama, perlakuan khusus pada sampel, dan ahli dalam mempresentasikan hasil. Metode baru perlu dikembangkan untuk memberikan solusi terhadap kendala-kendala yang ditemui pada metode-metode sebelumnya.

Sebuah metode alternatif diperkenalkan oleh Murni, S dkk (2012) menggunakan metode elektrooptis untuk menentukan jenis minyak goreng nabati. Sampel yang digunakan adalah minyak goreng dari jagung, kelapa, palem dan zaitun. Metode ini memanfaatkan medan listrik untuk mengamati sifat polarisasi larutan. Hasilnya, semakin besar medan listrik yang digunakan, perubahan sudut polarisasi juga semakin besar. Perbedaan sudut polarisasi mengindikasikan jenis-jenis minyak goreng. Penelitian ini kemudian dilanjutkan oleh Firdausi dkk (2013) untuk menentukan mutu minyak goreng dengan metode elektrooptis. Uji dilakukan terhadap jenis minyak goreng nabati yang masih layak pakai dan yang sudah kadaluarsa. Hasilnya, minyak goreng yang sudah kadaluarsa memiliki sudut polarisasi yang lebih besar dibanding minyak goreng yang masih layak pakai. Keberadaan radikal bebas sebanding dengan perubahan sudut polarisasi sehingga bisa digunakan untuk menentukan mutu minyak goreng (Widyastuti, 2009). Adanya penggunaan minyak goreng hewani oleh masyarakat menjadi permasalahan yang menarik untuk diteliti dengan membedakan beragam minyak goreng hewani menggunakan metode elektrooptis. Pencampuran minyak sawit dengan minyak hewani yang dilakukan oleh pengusaha kuliner untuk menimbulkan rasa yang lebih gurih bisa menimbulkan kekhawatiran konsumen karena lemak jenuh pada minyak hewani lebih besar dibanding minyak biasa. Oleh karen itu, perlu dilakukan penelitian untuk mengetahui perbedaan minyak sawit murni dan campuran.

Tujuan penelitian ini adalah untuk mempelajari perbedaan minyak sawit murni dan minyak sawit campuran melalui perubahan sudut polarisasi alami dan elektrooptis. Adapun manfaat yang dapat diperoleh dari penelitian ini diantaranya memahami sifat polarisasi cahaya, memberi informasi pada masyarakat mengenai perbedaan jenis-jenis minyak goreng hewani dengan metode elektrooptis dan mengembangkan metode ini untuk menguji campuran minyak sawit dengan berbagai campuran minyak hewani.

\section{METODE PENELITIAN}

Penelitian ini dilakukan dengan komponen utama terdiri dari dua buah polarisator yang berfungsi untuk memilih arah medan listrik dan cahaya (polarisator pertama) dan analisator sebagai penentu besar perubahan polarisasi cahaya (polarisator kedua). Sumber cahaya yang digunakan adalah lampu pijar 60 watt. Skema penelitian ditunjukkan oleh Gambar 1. Sampel yang digunakan adalah minyak sawit murni dan campuran minyak sawit dan minyak ayam, minyak sawit dan minyak babi, dan campuran minyak sawit dan minyak sapi. Minyak campuran ini terdiri dari 3 $\mathrm{ml}$ minyak sawit ditambahkan dengan masingmasing minyak hewani. Minyak campuran ini dipanaskan di oven agar tidak membeku kemudian dikocok agar campuran menjadi homogen. Sampel ditaruh di dalam kuvet yang berada di antara kedua polarisator.

Sebelum melakukan pengujian, peralatan terlebih dahulu dikalibrasi dengan mengukur sudut polarisasi kuvet tanpa sampel. Apabila tidak terjadi perubahan sudut, berarti peralatan siap digunakan. Kemudian dilakukan pengujian terhadap sampel dengan menggunakan polarisasi alami, dimana pelat logam sejajar yang berada di antara kuvet tidak dialiri arus listrik. Sampel minyak sawit murni diukur perubahan sudut polarisasinya sebanyak 10 kali dan 
kemudian diambil data terbaik yang merupakan rata-ratanya. Hal yang sama dilakukan untuk sampel minyak campuran. Selanjutnya, pengujian dilakukan dengan menggunakan metode elektrooptis. Caranya sama dengan polarisasi alami dengan menyalakan catudaya dengan tegangan $6 \mathrm{kV}$.

\section{HASIL DAN PEMBAHASAN}

Hasil pengujian yang dilakukan terhadap minyak sawit murni dan minyak campuran dengan polarisasi alami dan elektrooptis ditampilan di Tabel 1.

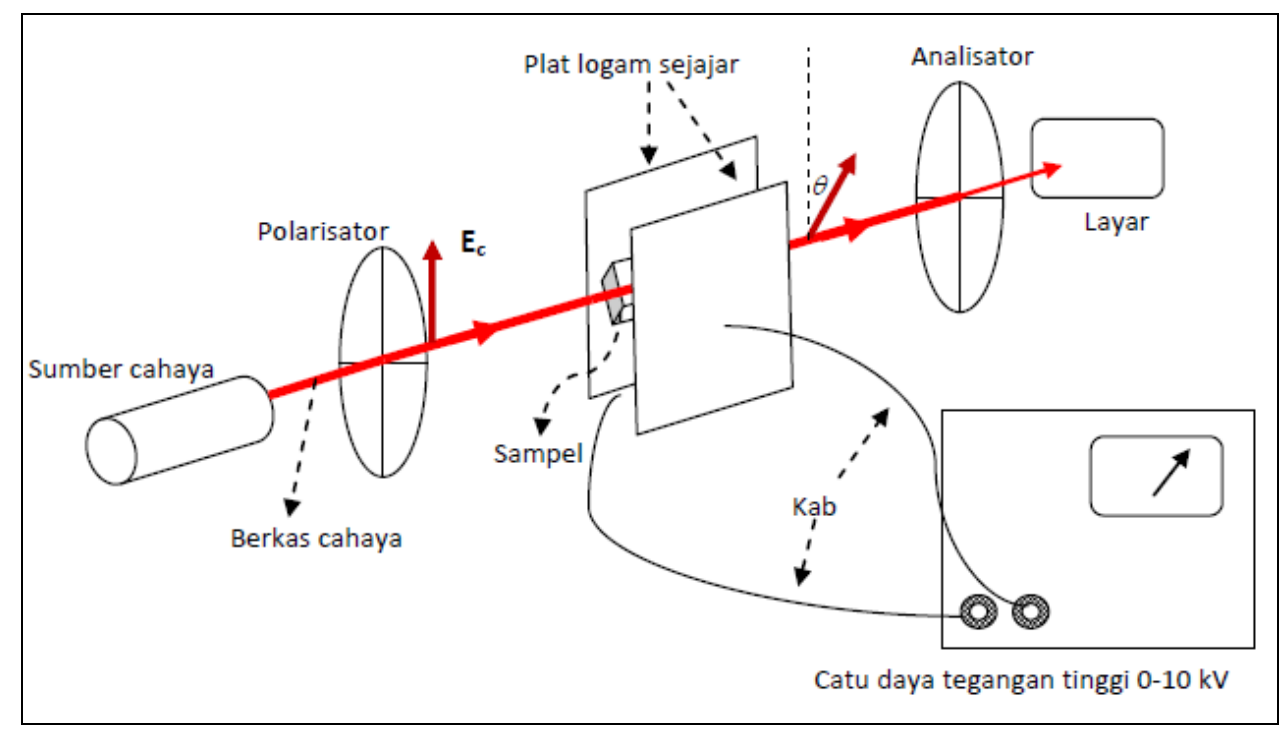

Gambar 1. Skema rangkaian penelitian

Tabel 1. Data perubahan sudut polarisasi dari sampel minyak sawit murni dan campuran

\begin{tabular}{lcc}
\hline \multirow{2}{*}{ Jenis minyak } & \multicolumn{2}{c}{ Polarisasi } \\
\cline { 2 - 3 } & Alami & Elektrooptis \\
\hline Minyak sawit murni & 0.4 & 1.1 \\
Minyak sawit + minyak ayam & 0.9 & 1.5 \\
Minyak sawit + minyak babi & 1.1 & 1.7 \\
Minyak sawit + minyak sapi & 1.5 & 3 \\
\hline
\end{tabular}

Hasil pengukuran ini digambarkan dengan menggunakan grafik sebagai perbandingan seperti ditunjukkan Gambar 2. Dari gambar 2 terlihat bahwa minyak goreng campuran menghasilkan perubahan sudut polarisasi yang lebih besar dibandingkan dengan minyak sawit murni baik dengan metode polarisasi alami maupun elektrooptis. Perubahan sudut polarisasi ini sebanding dengan kandungan asam lemak jenuh yang dimiliki oleh minyak campuran. Kandungan asam lemak jenuh minyak hewani lebih besar dibandingkan minyak nabati (Hermanto S, dkk, 2014) sehingga sudut polarisasi ini dapat digunakan untuk menunjukkan perbedaan jenis minyak goreng di atas. Pemanasan sampel agar mencair juga menambah jumlah kandungan asam lemak jenuh sehingga sudut polarisasi meningkat. Hasil ini diperkuat oleh hasil uji titrasi berupa 
Idrus, H., Kaltsum, U., Firdausi, K.S. 2017. Perubahan Sudut Polarisasi Alami Dan Elektrooptis Minyak Sawit Yang Dicampur Berbagai Minyak Hewani. Journal of Sainstek 9(1): 8-13

kandungan ALB dan bilangan peroksida seperti yang ditampilkan dalam Tabel 2.

Bilangan peroksida (PV) menyatakan indeks jumlah minyak yang telah mengalami oksidasi sehingga digunakan sebagai salah satu parameter untuk menentukan mutu minyak goreng. Peroksida terbentuk karena adanya interaksi radikal bebas dengan oksigen, selanjutnya mengikat hidrogen dari asam lemak tak jenuh. Semakin tinggi PV, semakin buruk mutu minyak goreng.

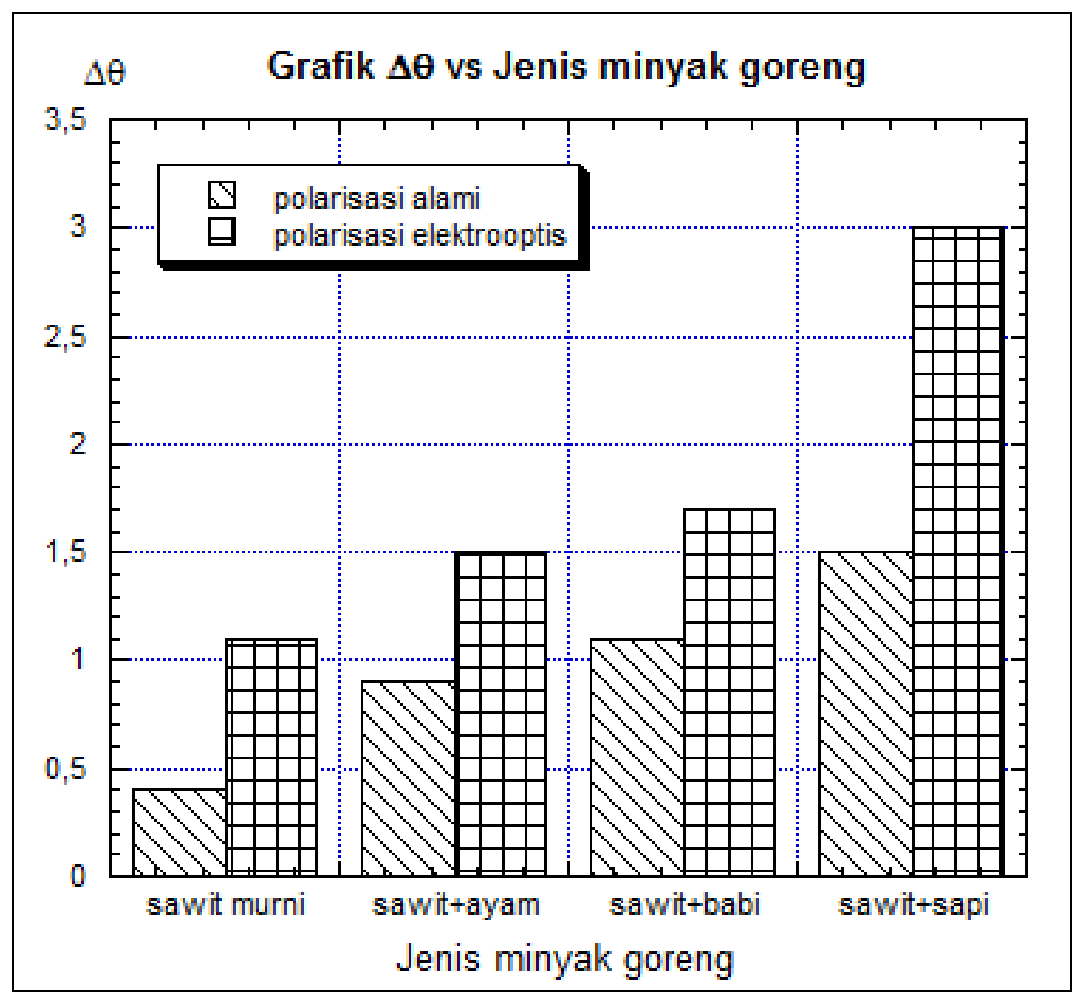

Gambar 2. Perubahan sudut polarisasi $(\Delta \theta)$ terhadap jenis minyak goreng

Hasil uji titrasi yang dilakukan oleh Hermanto S, dkk (2014) menunjukkan campuran minyak sawit dan minyak sapi memiliki ALB dan PV tertinggi. Hasil dari penelitian ini menunjukkan bahwa campuran minyak sawit dan minyak sapi memiliki perubahan sudut polarisasi terbesar, baik diuji dengan polarisasi alami maupun polarisasi elektrooptis. Dalam hal ini, polarisasi elektrooptis menghasilkan perubahan sudut polarisasi yang lebih besar dibandingkan dengan polarisasi alami. Dibandingkan dengan titrasi, metode polarisasi lebih sederhana dan singkat.

Tabel 2. Hasil uji kandungan asam lemak bebas (ALB) dan bilangan peroksida (PV)

\begin{tabular}{lcc}
\hline \multicolumn{1}{c}{ Jenis minyak } & ALB $(\%)$ & PV $(\mathrm{meq} / \mathrm{kg})$ \\
\hline Minyak sawit murni & 0.043 & 0.605 \\
Minyak sawit + minyak ayam & 0.045 & 0.640 \\
Minyak sawit + minyak babi & 0.049 & 0.675 \\
Minyak sawit + minyak sapi & 0.052 & 0.703 \\
\hline
\end{tabular}


Perbandingan antara polarisasi alami dan elektrooptis menunjukkan bahwa perubahan sudut polarisasi elektrooptis lebih besar dari polarisasi alami. Hal ini dijelaskan dengan prinsip medan listrik. Ketika sampel diletakkan dalam ruang bermedan listrik Em (plat logam sejajar yang diberi beda potensial), medan listrik mengimbas molekul-molekul pada minyak sehingga mengalami polarisasi dan membentuk dipol listrik yang searah dengan medan listrik Em. Jika sampel tersebut dilewati cahaya yang terpolarisasi linear dengan medan listrik Ec, maka terjadi interaksi antara Em dan Ec (Firdausi, 2011). Interaksi tersebut membentuk resultan medan listrik $\mathbf{E}$ dengan perubahan sudut polarisasi $\Delta \theta$ yang ditunjukkan oleh Gambar 3.

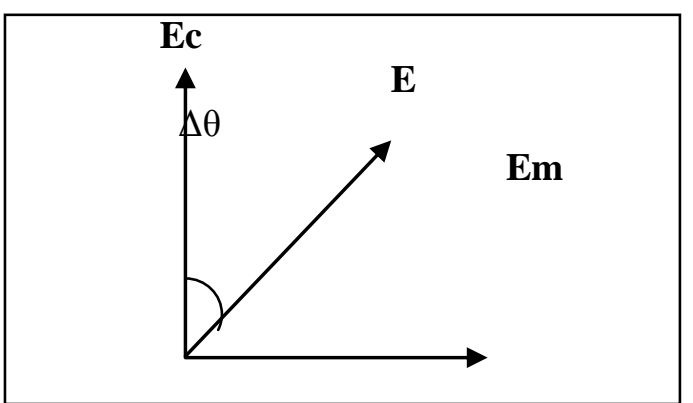

Gambar 3. Interaksi antara $\mathbf{E m}$ dan $\mathbf{E c}$ membentuk resultan $\mathbf{E}$

Pada polarisasi alami hanya terdapat Ec tidak ada Em, sehingga tidak ada resultan $\mathbf{E}$ yang menghasilkan perubahan sudut polarisasinya lebih kecil. Perubahan sudut polarisasi alami ditimbulkan oleh adanya interaksi cahaya dengan molekul asimetri minyak. Pada elektrooptis, semakin tinggi tegangannya, semakin besar nilai Em yang berakibat pada semakin besar perubahan sudut polarisasi. Oleh karena itu, perubahan sudut polarisasi pada elektrooptis lebih besar dibandingkan polarisasi alami. Pada sampel lain dengan berbagai variasi menunjukkan hasil yang sama, yakni perubahan sudut polarisasi elektrooptis lebih besar dibanding perubahan sudut polarisasi alami.

\section{KESIMPULAN}

Penambahan minyak hewani pada minyak sawit menghasilkan perubahan sudut polarisasi yang lebih besar dibandingkan dengan minyak sawit murni, baik dengan menggunakan metode polarisasi alami maupun polarisasi elektrooptis. Metode polarisasi elektrooptis menghasilkan perubahan sudut yang lebih besar dibandingkan metode polarisasi alami sehingga lebih mudah untuk membedakan minyak sawit murni dan minyak sawit campuran. Minyak hewani memiliki asam lemak jenuh yang lebih besar dari pada lemak nabati sehingga bisa dikatakan bahwa perubahan sudut polarisasi ini menunjukkan lemak jenuh yang terdapat pada minyak.

\section{DAFTAR KEPUSTAKAAN}

Firdausi KS. 2011.Pengembangan Metode Uji Baru untuk Penentuan Mutu Minyak Goreng Berdasarkan Sifat Elektrooptis, Tesis, Universitas Gadjah Mada,

Firdausi KS, Heri S, Ria A, Sri M, Ari B. 2013. Electrooptics Effect as a New Proposed Method for Determination of Vegetable Oil Quality and a Study of Most 
Idrus, H., Kaltsum, U., Firdausi, K.S. 2017. Perubahan Sudut Polarisasi Alami Dan Elektrooptis Minyak Sawit Yang Dicampur Berbagai Minyak Hewani. Journal of Sainstek 9(1): 8-13

Responsible Physical Processes, Proceeding from International Seminar on "New Paradigm and Innovation on Natural Sciences and Its Application" Faculty of Sciences and Mathematics, Diponegoro University.

Firdausi KS, Kuwat T, Ade IS. 2012. An Improvement of New Test Method for Determination of Vegetable Oil Quality Based on Electrooptics Parameter, Berkala Fisika Vol 15 No. 3, hal 77-86 Hermanto S, Anna M, Prita W. 2009. Analisis Tingkat Kerusakan Lemak Nabati dan Lemak Hewani Akibat Proses Pemanasan, Valensi, Volume 1, No.6, 262-268.
Murni S, Firdausi KS, Eko H, Ari B. 2012. Sifat Elektrooptis sebagai Parameter Indikasi Mutu Berbagai Jenis Minyak Goreng Kemasan, Berkala Fisika, Volume 15, N0.4, 119-122.

Sitepoe M. 2008. Corat-Coret Anak Desa Berprofesi Ganda, Cetakan Pertama, Jakarta: Kepustakaan Populer Gramedia, p.15-18.

SNI. 2013. "Minyak Goreng”, 3741-1013, Badan Standardisasi Nasional.

Nina W, Much A, Firdausi KS. 2009. Studi Efek Elektrooptis Pada Minyak Goreng, Berkala Fisika, Volume 12, No.2, hal 6368 